\title{
Flood mapping under an extreme event in a large shallow lake influenced by flood pulse in Southeast Asia
}

\author{
Sokly Siev 1,2,3,5, *, Vannak Ann ${ }^{2,4}$, Takashi Nakamura ${ }^{1}$, Hideto Fujii ${ }^{5}$ and Chihiro Yoshimura ${ }^{6}$ \\ ${ }^{1}$ Department of Transdisciplinary Science and Engineering, Tokyo Institute of Technology, Japan \\ ${ }^{2}$ Water and Environment Unit, Research and Innovation Center, Institute of Technology of Cambodia, Cambodia \\ ${ }^{3}$ Faculty of Chemical and Food Engineering, Institute of Technology of Cambodia, Cambodia \\ ${ }^{4}$ Faculty of Hydrology and Water Resources Engineering, Institute of Technology of Cambodia, Cambodia \\ ${ }^{5}$ Faculty of Agriculture, Yamagata University, Japan \\ ${ }^{6}$ Department of Civil and Environmental Engineering, Tokyo Institute of Technology, Japan
}

\begin{abstract}
Tonle Sap Lake (TSL) in Cambodia is the largest shallow lake in Southeast Asia. Influenced by flood pulse system of the Mekong River, TSL provides diverse benefits including ecosystem services, ecological functioning, and flood water storage in the floodplains. However, extreme events (e.g., flooding) due to rising water level caused by dam break and/or heavy rainfall in the Mekong River Basin could threaten the ecosystems of the lake, community health and economic growth in the region. Flood mapping under such extreme event could be informative in the flood risk and emergency management. In this study, we aim to develop a flood risk boundary map in TSL using an existing 2D hydrodynamic model (Caesar-Lisflood, CL) with rising water levels estimated by Gumbel distribution. As a result, the extreme water level of $1 \%$ chance (or 100-year flood return period) exceeding the annual maximum water level at Prek Kdam station was approximately $11.38 \mathrm{~m}$ resulting in the largest inundation area of $15193 \mathrm{~km}^{2}$. Overall, the employed method and flood risk mapping are useful for the decision makers to manage flood risks and emergency in the lake. This is to anticipate the consequences of a possible rising water level by an extreme event.
\end{abstract}

\section{Introduction}

Quantifying the risk of flooding is the central challenges for planning regulation, insurability standards and pricing, and disaster management. Flood frequency analysis is a one of the quantitative assessment methods for the flood risk management by quantifying the magnitude of flood water levels in terms of nominal return-periods, like the 1 in 100-year flood. This information is essential for the "design floods" in the planning regulation, and other flood risk management policy making [1]. However, the method reflects the flood information only at any gauge stations having a long-term historical data (e.g., discharge, water level), but the spatial information on flooding cannot be produced. For instance, the flood water level for 100-year return period can be estimated but its flood extent area cannot be produced. Unless additional analysis is applied, such as overlying the flood water level over the topography map of the investigating area, the area under flood water level (flood water level > topography) can be quantified. This simple application does not represent physical processes of flood or hydraulic meaning (e.g., movement of flood water level, flood duration, time-lag) and could overestimate the flood extent area when the investigating area is large. The application of hydrodynamic model can overcome above limits in term of spatial scale and physical meaning under any extreme flood events. Therefore, this study attempted to develop a flood risk map using flood frequency analysis and hydrodynamic model in a large shallow lake located in Southeast Asia as a case study.

Located in Southeast Asia, Tonle Sap Lake (TSL) is the largest shallow lake surrounded by an extensive floodplain (Fig. 1). TSL is linked to the Mekong River (MR) via the Tonle Sap River. Water surface area and water depth of TSL fluctuate vastly between the dry and wet seasons as result of the flood pulse system of the MR. The lake area has abundant resources such as forests, fisheries, wetlands, agricultural land, and others. TSL is also a crucially important source of livelihood in Cambodia. More than one million people are living in the surrounding area and wetlands of TSL and highly rely on agriculture and fisheries. However, the impact of climate change and anthropogenic activities (e.g., water-related infrastructure development, hydropower dams) in the MR basin could impose a significant change in flow regime and water level at its downstream as well as TSL [2]. For example, extreme flood and drought in MR basin is reported to frequently occur as a result of the interdecadal change in the precipitation and water discharge which has a strong link to El Niño-Southern Oscillation (ENSO) [3]. Moreover, the accident of hydropower dam break could threaten infrastructure, ecosystems of the lake, community health and economic growth in the region. Therefore, this study evaluates and develops a flood risk map due to rising water level possibly caused by dam

* Corresponding author: sievsokly@yahoo.com 
break and/or heavy rainfall in the MR basin. This study is a part of the scenario analysis under the water environmental analytical tool (WEAT) in the Science and Technology Research Partnership for Sustainable Development (SATREPS) project entitled "Establishment of Environmental Conservation Platform of Tonle Sap Lake supported by Japan International Cooperation Agency (JICA) and Japan Science and Technology Agency (JST).

\section{Materials and Methods}

The study composed of two main components including flood frequency analysis (e.g., Gumbel distribution) and application of 2D hydrodynamic model (Caesar-Lisflood, $\mathrm{CL}$ ). The former component describes the flood frequency analysis at Prek Kdam station in order to estimate extreme flood water levels based on the historical recorded dataset. The estimated flood water levels were then used in CL as the input to simulate the inundation areas under extreme events.

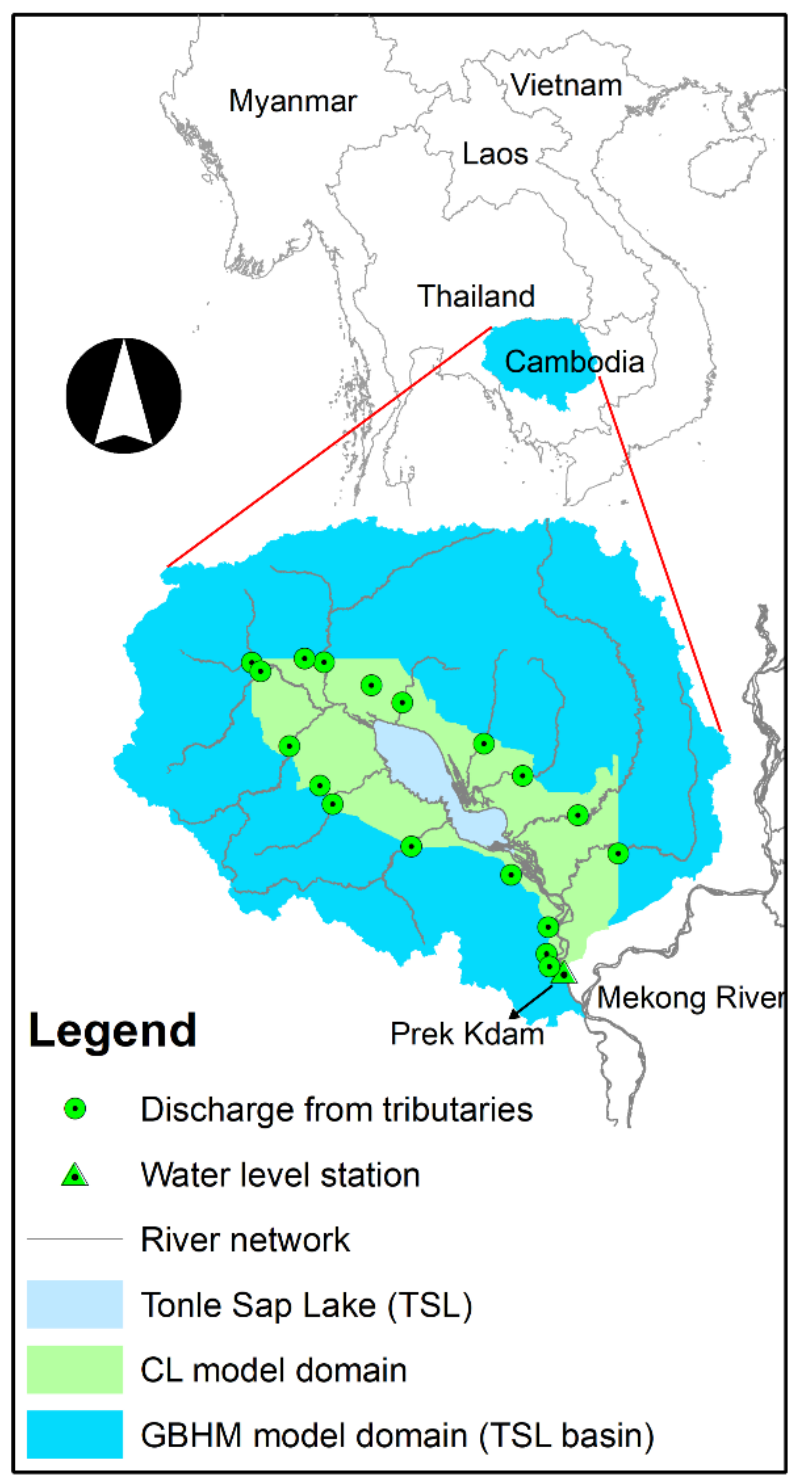

Fig. 1. Study area and computational domain of the integrated models

\subsection{Study area}

The unique characteristics of TSL are large, shallow, and reversal flow. In the dry season, TSL covers about $120 \mathrm{~km}$ of length, $35 \mathrm{~km}$ of width, $2 \mathrm{~m}$ of average water depth with an approximately $2500 \mathrm{~km}^{2}$ of water surface area. The water in TSL originates mainly from two sources, the surrounding tributaries and the MR (Fig. 1). For instance, 11 main tributaries flow into TSL directly (Fig. 1). In addition, the MR provides a significant amount of water volume to TSL during the wet season through reversal flow or flood pulse creating a unique hydrological environment. Thus, TSL plays an important role in water storage and exchange between the two systems. Unlike other shallow lakes around the world, water surface area and water depth of TSL increase greatly during the storage period (e.g., wet season) and cover about $250 \mathrm{~km}$ of length, $100 \mathrm{~km}$ of width, $10 \mathrm{~m}$ of average water depth with a surface area of about $17,500 \mathrm{~km}^{2}$ (Fig. 1). The inflow of water discharge into the lake ranged: 104-7032 $\mathrm{m}^{3} / \mathrm{s}$, while the outflow of water from the lake ranged: $380-8176 \mathrm{~m}^{3} / \mathrm{s}$. Moreover, in the lake area, the weather is characterized by the monsoon. During the wet season (May-Oct), the direction of winds is predominantly from the southwest and from the northeast during the dry season (Nov-Apr). Wind speed is about $2-3 \mathrm{~m} / \mathrm{s}$ on average, which is typically low, except during short storms. The annual mean rainfall ranges from $1300 \mathrm{~mm}$ in the south to $1500 \mathrm{~mm}$ in the northern part of the lake area. Water temperature of the lake ranges between 28 and $33{ }^{\circ} \mathrm{C}[4]$.

\subsection{Flood frequency analysis}

Long-term daily water level at Prek Kdam station from 1960 to 2013 was provided by Mekong River Commission. The annual maximum water level was then extracted from the long-term daily water level to perform flood frequency analysis, in total 53 annual maximum water levels were extracted (Fig. 2).

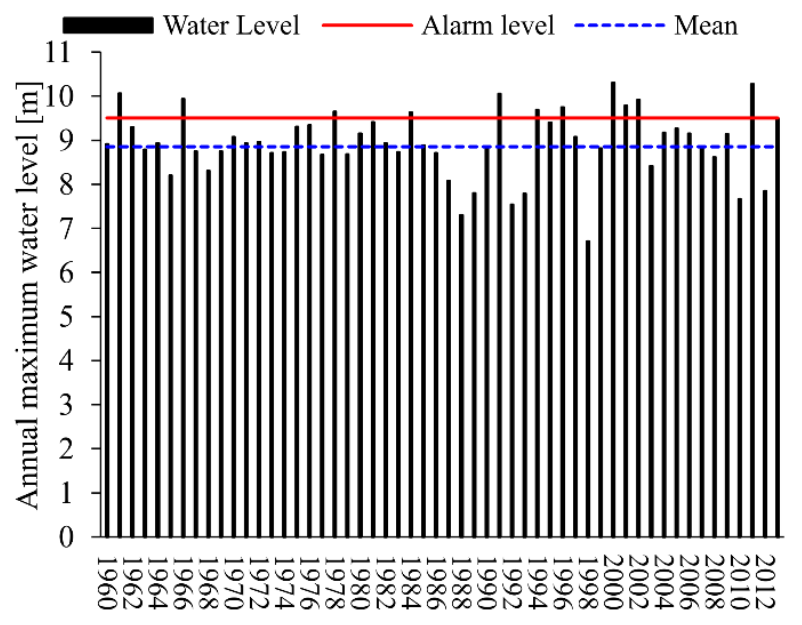

Fig. 2. Annual maximum water level at Prek Kdam station.

In the present case, we decided to use annual maximum water level data fitting with a Gumbel 
distribution which seems to be a common choice for the extreme value flood frequency analysis [5-7]. Generally, the application of Gumbel distribution is used to fit the probability distribution of the maximum value from a number of samples. From the probability distribution, it allows to us to estimate any extreme values at very low probability of occurrence. For instance, we can estimate a maximum water level or water discharge in a river at $1 \%$ chance or even lower from the fitted probability distribution or graph [5]. The Gumbel probability distribution is expressed as:

$$
F(x)=\exp [-\exp (-y)]=e^{-e^{-y}}
$$

where $F(x)$ is the probability distribution function of random variable $x$ and $y$ is a reduced variable

The probability of exceedance of the excluded events related to return period $(T)$ is presented by:

$$
F_{1}(x)=1-F(x)=\frac{1}{T}
$$

The combination of Equations (1) and (2) gives Equation (3) in the following form:

$$
\frac{1}{T}=1-e^{-e^{-y}}
$$

The reduced variable (y) may be derived from the Equation (3) as below:

$$
y=-\ln \left\{\ln \left[\frac{T}{(T-1)}\right]\right\}
$$

Equation (5) is used to estimate the statistical variate $(y)$ as below:

$$
y=\overline{y_{n}}+K \times \sigma_{n}
$$

where $\overline{y_{n}}=$ Gumbel's reduced mean variable, $\sigma_{n}=$ standard deviation of the sample size and $K$ is frequency factor and can be expressed as in Equation (6) below:

$$
K=\frac{y-\overline{y_{n}}}{\sigma_{n}}=\frac{-\ln \left\{\ln \left[\frac{T}{(T-1)}\right]\right\}-\overline{y_{n}}}{\sigma_{n}}
$$

\subsection{Hydrodynamic model}

In this study, an existing 2D hydrodynamic model, Caesar Lisflood (CL), is applied and simulate and inundation area in TSL and its floodplain by integrating in the input from the tributaries and also from the MR. Daily discharge from the tributaries were simulated using geomorphology-based hydrological model [8-9], resulting in 18 input points (Fig. 1). Water levels at Prek Kdam station were input as boundary condition from the MR (Fig. 1). The CL model has been calibrated and validated during the period of 2003-2013, having a good agreement between observed and simulated water level in the lake. Further details about the CL model and model setting can found in the previous study [9].

The magnitude of maximum water levels corresponding to the probability of $1 \%$ chance is termed 100 -year flood return period. In other word, the return period of 100-year flood is $T=100$. Therefore, the probability of a flood exceeding or equalling to magnitude of maximum water levels in any given one year period is $1 / T$ or 0.01 or $1 \%$ chance. Similarly, other return periods and exceeding probability are defined the same manner.

To understand the effect of the rising water level at Prek Kdam station, the extrapolated extreme water levels in section 2.2 were then used as a boundary condition in CL model to simulate the inundation areas of TSL while other parameters and boundary conditions were kept the same for both normal and rising water level conditions.

The inundation area of the normal flood year in 1999 in TSL was considered as a normal condition and used to compare with the rising water level conditions. The conditions consisted of 10 different scenarios having maximum water levels exceeding $1 \%, 1.1 \%, 1.25 \%$, $1.4 \%, 1.7 \%, 2 \%, 5 \%, 10 \%, 20 \%$, and $40 \%$ corresponding to $100,90,80,70,60,50,20,10,5$ and 2.5 -year return period, respectively. Finally, a flood risk map was produced based on those inundation areas.

\section{Results and discussion}

\subsection{Extreme value of water level estimation}

The maximum annual water levels at Prek Kdam station were statistically analysed and fitted for a period of 53years (1960-2013) (Fig. 3). The mean instantaneous water level is $8.85 \mathrm{~m}$ with a coefficient of variability $(\mathrm{CV})$ of $10.40 \%$ (less variability) (Fig. 2). The estimated water levels for the different return periods were tabulated in Table 1. The estimated extreme water level for the 100year return period was $11.38 \mathrm{~m}$ with $1 \%$ possible chance occurring in any given year or in other words, there could be $99 \%$ chance that the rising water level is less than 11.38 $\mathrm{m}$.

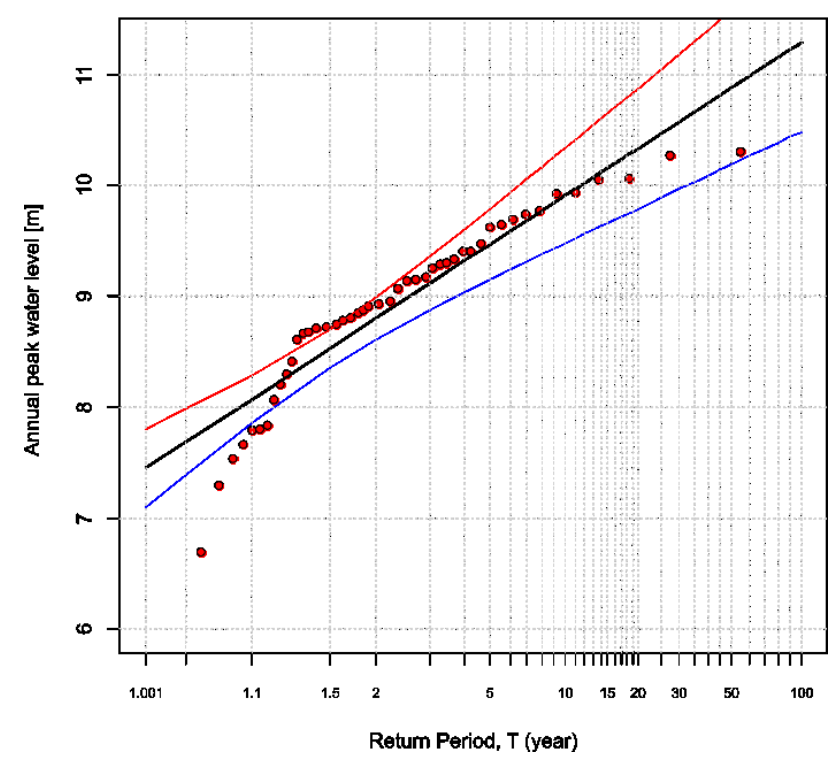

Fig. 3. Annual maximum water level at different return period at Prek Kdam station 
Table 1. Result of flood frequency analysis

\begin{tabular}{|c|c|c|}
\hline $\begin{array}{c}\text { Return period } \\
(\mathrm{T}) \text { [year] }\end{array}$ & $\begin{array}{c}\text { Exceedance } \\
\text { Probability }(1 / \mathrm{T})[\%]\end{array}$ & $\begin{array}{c}\text { Maximum water } \\
\text { level [m] }\end{array}$ \\
\hline 100 & 1 & 11.38 \\
\hline 90 & 1.1 & 11.32 \\
\hline 80 & 1.25 & 11.24 \\
\hline 70 & 1.4 & 11.16 \\
\hline 60 & 1.7 & 11.06 \\
\hline 50 & 2 & 10.95 \\
\hline 20 & 5 & 10.36 \\
\hline 10 & 10 & 9.91 \\
\hline 5 & 20 & 9.44 \\
\hline 2.5 & 40 & 8.92 \\
\hline
\end{tabular}

\subsection{Flood risk boundary map}

The hydrodynamic simulation results under different rising water level scenarios are showed in Figure 4. The simulated inundation area accounted for $15193 \mathrm{~km}^{2}$, $15155 \mathrm{~km}^{2}, 15115 \mathrm{~km}^{2}, 15066 \mathrm{~km}^{2}, 15018 \mathrm{~km}^{2}, 14928$ $\mathrm{km}^{2}, 14674 \mathrm{~km}^{2}, 14444 \mathrm{~km}^{2}, 14117 \mathrm{~km}^{2}$, and $13613 \mathrm{~km}^{2}$ for the return periods of $100,90,80,70,60,50,20,10,5$, and 2.5-year, respectively. Compared to the inundation area $\left(13510 \mathrm{~km}^{2}\right)$ of normal flood year (1999) in TSL, the inundation areas increased by $12.5 \%, 12.2 \%, 11.9 \%$, $11.5 \%, 11.2 \%, 10.5 \%, 8.6 \%, 6.9 \%, 4.5 \%$, and $0.8 \%$, respectively. The boundary edge of all flood maps is in the water depth of less than $2 \mathrm{~m}$ (Fig. 4).

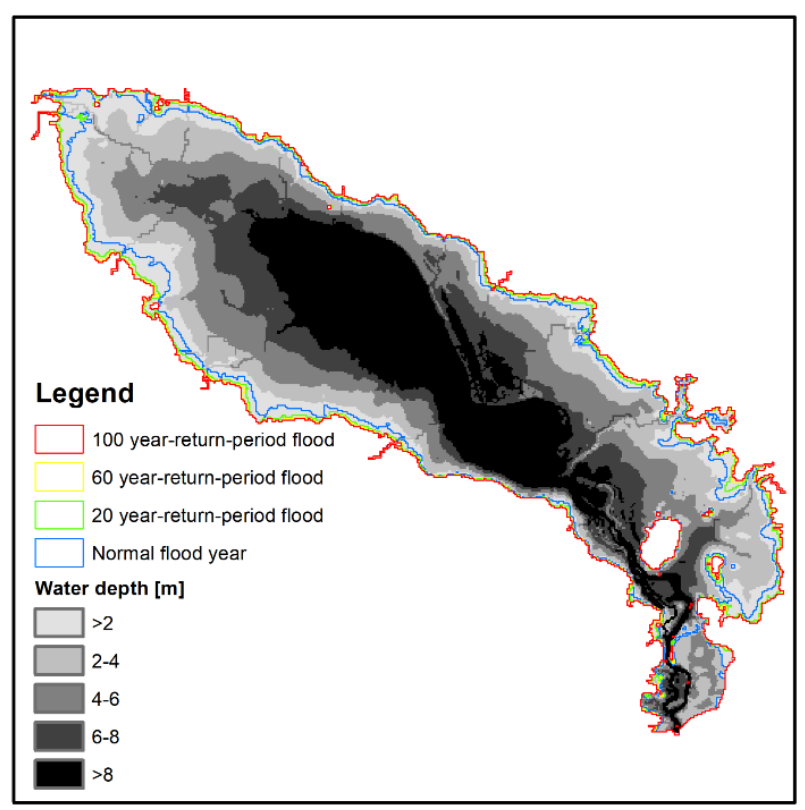

Fig. 4. Flood risk map in Tonle Sap Lake

The implication of the results is that the inundation area could increase by $12.2 \%$ once in 100 chance of occurring in any given year and the increased area can be seen in between red and blue line in Figure 4. The results serve as an example of application of flood frequency analysis and hydrodynamic model in an integrated manner to explain an extreme event of flooding in a spatial and physical meaning way. This method is also capable of assessing the impact of some scenarios on inundation areas. For instance, in this study, the maximum water levels for each simulation were set to prolong for 5 days during flooding period to quantify the extended inundation areas. Similarly, the duration of flooding can be set for any number of days according to the purposes and scenarios being accessed.

\section{Conclusion}

This study investigated inundation areas in TSL under the extreme event scenarios based on flood frequency analysis and hydrodynamic model application. A flood risk map boundary was produced under those scenarios. The method used and flood risk mapping are useful for the decision makers to manage flood risks and emergency in the lake. This is to anticipate the consequences of a possible rising water level by an extreme event.

This research was funded by the JST-JICA's Science and Technology Research Partnership for Sustainable Development (SATREPS), Grant No: JPMJSA1503.

\section{References}

1. B. Parkes, D. Demeritt, J. Hydrol. 540, 1189-1208 (2016)

2. M. E. Arias, T. A. Cochrane, M. Kummu, H. Lauri, G. W. Holtgrieve, J. Koponen, T. Piman, Ecol. Modell. 272, 252-263 (2014)

3. J. M. Delgado, B. Merz, H. Apel, Hydrol. Earth Syst. Sci.16, 1533-1541 (2012)

4. S. Siev, H. Yang, T. Sok, S. Uk, L. Song, D. Kodikara, C. Oeurng, S. Hul, C. Yoshimura, Sci. Total Environ. 631-632, 597-607 (2018)

5. F. Onen, T. Bagatur, Arab. J. Sci. Eng. 42, 38953906 (2017)

6. J. H. Ryu, J. Kim, Water 11, 1-17, (2019)

7. M. S. Bhat, A. Alam, B. Ahmad, B. S. Kotlia, H. Farooq, A. K. Taloor, S. Ahmad, Quat. Int. 507, 288 294 (2019)

8. T. Tanaka, H. Yoshioka, S. Siev, H. Fujii, Y. Fujihara, K. Hoshikawa, S. Ly, C. Yoshimura, Water 10, 1213 (2018)

9. S. Siev, M. Sato, I. Yoneda, R. Khanal, S. Ly, H. Fujii, C. Yoshimura, The 11th Regional Conference on Environmental Engineering 2018 (RCEnvE-2018) and The 3rd International Symposium on Conservation and Management of Tropical Lakes (Institute of Technology of Cambodia, Phnom Penh, 2018) 